\title{
Spatial Effect Research on Educational Output and Economic Growth in China
}

\author{
Wuyuan Sun, Jiayun Ma \\ The College of Economics, Jinan University, Guangzhou, China \\ Email: 18826236616@163.com
}

Received 8 April 2016; accepted 11 June 2016; published 14 June 2016

Copyright @ 2016 by authors and Scientific Research Publishing Inc.

This work is licensed under the Creative Commons Attribution International License (CC BY). http://creativecommons.org/licenses/by/4.0/

\section{cc) (i) Open Access}

\begin{abstract}
This thesis is to study spatial effect of education output on economic growth through the use of spatial measurement technique. According to the study: there's the presence of spatial spillover effects in human capital, economic growth, and others; in previous years, human capital depended on mainly the employers with junior school education or below; in recent years, with the reduction of employers with junior school education or below, employers with regular higher education can best promote the economic growth. However, it's very difficult for human capital with vocational education to promote economic growth, especially in recent years. Therefore, from the perspective of long-term economic growth, China should focus on culturing professional talents and put more resources into the development of vocational education while developing the higher education.
\end{abstract}

\section{Keywords}

Educational Output, Economic Growth, Spatial Effect

\section{Introduction}

A large number of China's labor forces in recent years are mainly provided by two education systems of regular higher education, vocational and technical education. The human capital as an important element affects economic growth, and the different education levels of labor forces will also affect the economic growth. Beneficiaries of higher education have stronger adaption to new technologies and ability of creation, the economic growth rate of the economies with rapid development of vocational education is lower than that of the economies taking the priority of developing the higher education. In recent years, China has been in short supply of all kinds of the skilled personnel, and some people call such phenomenon as "shortage of skilled workers." The experts assert that if the shortage situation of the skilled personnel is left unresolved, it will inevitably become the bottleneck affecting sustained and healthy development of China's economy. With China's great success in the 43rd World 
Skills Competition: 5 gold medals, 6 silver models, 3 bronze medals and 12 prizes for excellence, the national authorities have given a high priority to the skills education. According to the Vice Minister of the Ministry of Education Lu Xin, the Ministry of Education will complete transformation of more than 600 local undergraduate colleges to be application technology and vocational education types. This thesis used the panel data of 31 provinces during 2006-2014, and spatial measurement technology to understand the spatial effect of different educational outputs on economic growth. The educational output studied in this thesis refers to the number of graduates provided by different types of education.

\section{Model Construction and Relevant Theory}

\subsection{Design of Econometric Model}

Cobb-Douglas production function has been the most common production function in the literature of analyzing economic growth, namely:

$$
Y_{i t}=A_{i t} K_{i t}^{\alpha} L_{i t}^{\beta}
$$

Wherein, $Y_{i t}$ represents economic output, $K_{i t}$ represents physical capital investment, $L_{i t}$ represents investment in human capital, $\alpha, \beta$ respectively represents the elasticity of physical capital and human capital to economic output, $A_{i t}$ represents total factor productivity. The author in this thesis takes a reference of improvement of classic Cobb-Douglas production function made by An Xuehui (2002), Mao Shengyong (2010) [1] et al., and believes that human resources depend on not only the number of employees, but also the quality of employment, so the author divides the labor force into labors with junior school education or below $\left(L_{1}\right)$, labors with vocational and technical education $\left(L_{2}\right)$ and labors with regular higher education $\left(L_{3}\right)$. Therefore, the function becomes:

$$
Y_{i t}=A_{i t} K_{i t}^{\alpha} L_{1 i t}^{\beta_{1}} L_{2 i t}^{\beta_{2}} L_{3 i t}^{\beta_{3}}
$$

Select the logarithm from the above model to obtain the following model:

$$
\ln Y_{i t}=\ln A+\alpha \ln K_{i t}+\beta_{1} \ln L_{1 i t}+\beta_{2} \ln L_{2 i t}+\beta_{3} \ln L_{3 i t}
$$

\subsection{Indicator Selection and Data Description}

The author in this thesis adopts the classic Cobb-Douglas production function and adds the innovation efficiency of the first stage for the spatial econometric analysis. Taking into consideration of the meaning of each index of the production function and taking a reference to the indicator selection conducted by Fan Gang (2011) [2] et al in the study of economic growth. This thesis considers the year 2004 as a constant price to select constant price GDP as the indicator of economic output, and the constant price physical capital stock $K$. Perpetual inventory method is adopted for physical capital $K$, namely $K_{i t}=I_{i t}+(1-\alpha) K_{i t-1}, I_{i t}$ is the investment amount of fixed assets for each year, the processing approach of depreciation rate $\alpha$ is the same to that of Wang Xiaolu, Fan Gang (2009) [3], namely to set $\alpha=5 \%$, and take fixed asset investment of 2004 as the initial value to calculate physical capital stock during 2005-2013, and also treat 2004 as the constant price. Since the education degree of the number of employees in China Population and Employment Statistics Yearbook is divided into several categories of no schooling, elementary education, junior school education, senior school education, college education, undergraduate and graduate education, and there's no number of employees with vocational and technical education. Through the calculation of proportion $M_{i t}$ of the number of graduates in vocational and technical colleges of provinces each year and the number of graduates in regular higher schools, the author believes that the proportion of number of graduates of the two education systems is approximately equal to the proportion of the number of employees, and therefore the approximate number of employees with vocational and technical education can be obtained in the way the proportion $M_{i t}$ is multiplied by the number of employees with regular higher school education. Wherein, $L_{1 i t}$ is the sum of number of employees with no schooling, primary and junior school education in $\mathrm{t}$ term of I province; $L_{2 i t}$ is for $M_{i t}{ }^{*} L_{3 i t} ; L_{3 i t}$ is the number of employees with college education, undergraduate and graduate education.

\subsection{Correlation Test of Panel Data Space}

In practical application study, the spatial autocorrelation index of Moran's I is often used to test whether there's 
the spatial correlation, and the corresponding calculation formula is shown as follows:

$$
\text { Moran's } \mathrm{I}=\frac{\sum_{i=1}^{n} \sum_{j=1}^{n} W_{i j}\left(Y_{i}-\bar{Y}\right)\left(Y_{j}-\bar{Y}\right)}{S^{2} \sum_{i=1}^{n} \sum_{j=1}^{n} W_{i j}}
$$

Wherein, $S^{2}=\frac{1}{n} \sum_{i=1}^{n}\left(Y_{i}-\bar{Y}\right) ; \bar{Y}=\frac{1}{n} \sum_{i=1}^{n} Y_{i}, \quad Y_{i}$ represents the observed value of the area $i ; n$ is the total number of regions; $W_{i j}$ is a binary contiguous spatial weight matrix, representing any of corresponding elements, the purpose of using contiguity standards or distance criterion is to define mutual adjacency of the spatial objects, thus to be easy to place the relevant attribution in the geographic information system (GIS) database to the studied geographic space for contrast. Generally, the contiguity standard $W_{i j}$ is as follows:

$W_{i j}=1$, when the area $i$ is adjacent to the area $j$.

$W_{i j}=0$, when the area $i$ is not adjacent to the area $j$.

In the equation, $i=1,2, \cdots, n ; j=1,2, \cdots, m ; m=n$ or $n \neq m$ traditionally, all the diagonal elements of $W$ is ordered to be $W_{i i}=0$.

Mroan's I index [4] can be considered as the product sum of observed values of each region, which ranges between -1 and 1 , if the economic behavior between each region is positively correlated, the corresponding value should be larger; and the value should be smaller if the economic behavior is negatively correlated; the null space autocorrelation appears when there's mutually independent between distribution of attribution value and distribution of location data.

According to the calculation results of Moran's I index, the normal distribution assumption can be used to test whether there's the presence of spatial autocorrelation in $N$ regions, and the corresponding standardized form is as follows:

$$
Z(d)=\frac{\text { Moran's } I-E(I)}{\sqrt{\operatorname{VAR}(I)}}
$$

The expectation value and variance of the normal distribution Moran's I index can be calculated according to the distribution of spatial data:

$$
\begin{aligned}
& E_{n}(I)=-\frac{1}{n-1} \\
& \operatorname{VAR}_{n}(I)=\frac{n^{2} w_{1}+n w_{2}+3 w_{0}^{2}}{w_{0}^{2}\left(n^{2}-1\right)}-E_{n}^{2}(I)
\end{aligned}
$$

In the equation, $w_{0}=\sum_{i=1}^{n} \sum_{j=1}^{n} w_{i j}, w_{1}=\frac{1}{2} \sum_{i=1}^{n} \sum_{j=1}^{n}\left(w_{i j}+w_{j i}\right)^{2}, w_{2}=\sum_{i=1}^{n}\left(w_{i} .+w_{j} .\right)^{2}, w_{i}$. and $w_{j}$. is respectively the sum of row $i$ and column $j$ in spatial weight value matrix [2].

Formula (2) and (3) can be used to test whether there's the presence of the spatial autocorrelation in $N$ regions. If $Z$ value of normal statistics of Mroan's I index is greater than the critical value 1.96 of the normal distribution function at the 0.05 level, indicating that there's a significant positive correlation in the spatial distribution, the positive spatial correlation represents that similar characteristic value of neighboring regions appears the cluster trend.

\subsection{Spatial Lag Model (SLM) and Spatial Error Model (SEM)}

Spatial lag model focuses on discussing whether variables have the phenomenon of diffusion (spillover effects) in an area, and the corresponding expression is [4]:

$$
Y=\rho W y+X \beta+\varepsilon
$$

In the equation, $Y$ is the dependent variable; $X$ is exogenous independent variable matrix; $\rho$ is the relevant coefficient of spatial regression; reflecting the role of spatial dependence in observed value of the samples, 
namely, the affecting direction and extent of the observed value $W Y$ of the contiguity area on the observed value $Y y$ of the local region; and $W$ is the spatial weight matrix of $n \times n$ order, and it is usually expressed by the contiguity matrix; Wy is the spatial lag dependent variable, and $\varepsilon$ is the vector of a random error term.

Parameter $\beta$ reflects the impact of independent variable $X$ on dependent variable $Y$, and the spatial lag dependent variable $W y$ is an endogenous variable, reflecting the effect of spatial distance on regional behavior. The regional behavior is affected by cost of migration related to cultural environment and the spatial distance, which is with strong regional characteristics.

Mathematical expression of the spatial error model is:

$$
\begin{aligned}
& Y=X \beta+\varepsilon \\
& \varepsilon=\lambda W \varepsilon+\mu
\end{aligned}
$$

In the equation, $\varepsilon$ is the vector of random error term, $\lambda$ is the spatial error coefficient of the vector of $n \times 1$ cross-section dependent variable, and $\mu$ is normally distributed random error vector.

Parameter $\lambda$ measures the spatial dependence role of sample observed value, namely, the affecting direction and extent of observed value $Y$ of the contiguity region on observed value $Y$ of the local region, the parameter $\beta$ reflects the impact of the independent variable $X$ on the dependent variable $Y$. The spatial dependence of SEM presents in disturbance error term, which measures the affecting extent of contiguity area about the error impact of dependent variable on observed value of the local region.

\subsection{Direct Effect and Indirect Effect Theories}

The measurement method of principle of direct effect and indirect effect is conducted as follows by taking SLM model as an example [5].

First, SLM model in Equation (4) is rewritten as follows:

$$
\begin{gathered}
\left(I_{n}-\rho W\right) y=X \beta+\varepsilon \\
y=\sum_{r=1}^{k} S_{r}(W) x_{r}+V(W) \varepsilon \\
S_{r}(W)=V(W) I_{n} \beta_{r} \\
V(W)=\left(I_{n}-\rho W\right)^{-1}=I+\rho W+\rho^{2} W^{2}+\rho^{3} W^{3}+\cdots
\end{gathered}
$$

Then the total effect is $S_{r}(W)$, the average total effect is $n^{-1} S_{r}(W)=V(W) I_{n} \beta_{r}$.

The partial derivation of $x_{i r}$ is conducted according to the Equation (8) to obtain: $\frac{\partial y_{i}}{\partial x_{i r}}=S_{r}\left(W_{i i}\right)$, this value represents the impact of changes of an independent variable of the region $j$ on the dependent variable itself of the region, and this is direct effect [5].

The partial derivation of $x_{i r}$ is conducted according to the Equation (8) to obtain: $\frac{\partial y_{i}}{\partial x_{j r}}=S_{r}\left(W_{i j}\right)$. This value represents the changes of an independent variable of the region $j$ will potentially affect the dependent variable of region $\mathrm{j}$, and this is indirect effect.

Thus the expression of the average direct effect, average total effect and average indirect effect required in the study is shown as follows:

$$
\bar{M}(r)_{\text {direct }}=\frac{1}{n} \operatorname{trace}\left(S_{r}(W)\right), \bar{M}(r)_{\text {total }}=\frac{1}{n} S_{r}(W), \bar{M}(r)_{\text {indirect }}=\bar{M}(r)_{\text {total }}-\bar{M}(r)_{\text {direct }}
$$

\section{Empirical Analysis}

In order to make a dynamic comparison and study of the effect of employees of various education systems on economic growth, the author in this thesis respectively studies panel data samples of three time periods of 2006-2010, 2011-2014, and 2006-2014. First, Mroan's I is used to make the correlation test of various educational outputs and economic growths year by year, to obtain: 
Seen from Mroan's I index (Table 1), GDP, labors with junior school education or below, labors with vocational and technical education, labors with regular higher education of all regions show positive spatial correlation, showing some spatial clustering and the spatial correlation in recent years is more obvious. In addition, the labors with vocational and technical education and regular higher education show more obvious spatial clustering. Obviously, it's reasonable and necessary to use spatial measurement to build the model.

It can be seen from Mroan's I scatter diagram of GDP (Figure 1) that most cities are located in the first and third quadrants, indicating that most cities show high values surrounded by high values, Jiangsu and Shandong are more significant, but also the situation that low values are surrounded by low values. However, more significant situation of Guangdong province is about the high values surrounded by low values, Anhui is low values surrounded by high values, which is also in line with the status quo. In addition, it can be seen from Mroan's I scatter diagram of the three kinds of education (Figures 2-4) that most cities are located in the third quadrant, there are some cities located in the first and second quadrant, indicating that there's more obvious situation of low values surrounded by low values. Followed by is the situation of low values surrounded by high values, including the more significant situation of labors with vocational and technical education in Shandong and Zhejiang, which is the situation of high values surrounded by high values, and Anhui is the situation of low values surrounded by high values. However, among the labors with regular higher education, Beijing shows the situation of high values surrounded by low values; Jiangsu is the situation of high values surrounded by high values. It's visible that there's spatial heterogeneity for labor outputs of various educations.

Unlike the ordinary panel regression, the parameter estimation of spatial panel model is usually conducted by using maximum likelihood and moment estimation method. SLM and SEM model described in previous section are used to make SLM and SEM fitting of panel data of the three time periods respectively. Finally is to select the one with better fitting effects for analysis, the selection is made mainly based on checking which model has larger log-likelihood, and better variable significance, the models of various time periods obtained through fitting are better SEM models. The estimation results of various models calculated by using $\mathrm{R}$ language are shown

\begin{tabular}{cccccccccc}
\multicolumn{7}{l}{ Table 1. Correlation test. } \\
\hline Mroan's I & 2006 & 2007 & 2008 & 2009 & 2010 & 2011 & 2012 & 2013 & 2014 \\
\hline GDP & $0.208^{* * *}$ & $0.199^{* * *}$ & $0.2^{* * *}$ & $0.201^{* * *}$ & $0.209^{* * *}$ & $0.217^{* * *}$ & $0.219^{* * *}$ & $0.219^{* * *}$ & $0.22^{* * *}$ \\
L1 & $0.0941^{* *}$ & $0.0901^{* *}$ & $0.0884^{* *}$ & $0.0873^{* *}$ & $0.103^{* * *}$ & $0.101^{* * *}$ & $0.113^{* * *}$ & $0.139^{* * *}$ & $0.161^{* * *}$ \\
$L 2$ & $0.0362^{* *}$ & $0.0381^{* *}$ & $0.0645^{* *}$ & $0.0673^{* *}$ & $0.183^{* * *}$ & $0.166^{* * *}$ & $0.191^{* * *}$ & $0.224^{* * *}$ & $0.239^{* * *}$ \\
$L 3$ & $0.932^{* *}$ & $0.956^{* *}$ & $0.108^{* *}$ & $0.113^{* * *}$ & $0.145^{* * *}$ & $0.187^{* * *}$ & $0.202^{* * *}$ & $0.233^{* * *}$ & $0.237^{* * *}$ \\
\hline
\end{tabular}

Note: “*”, “**”, ““**” represent to pass the significance test at respective level of $10 \%, 5 \%$ and $1 \%$.

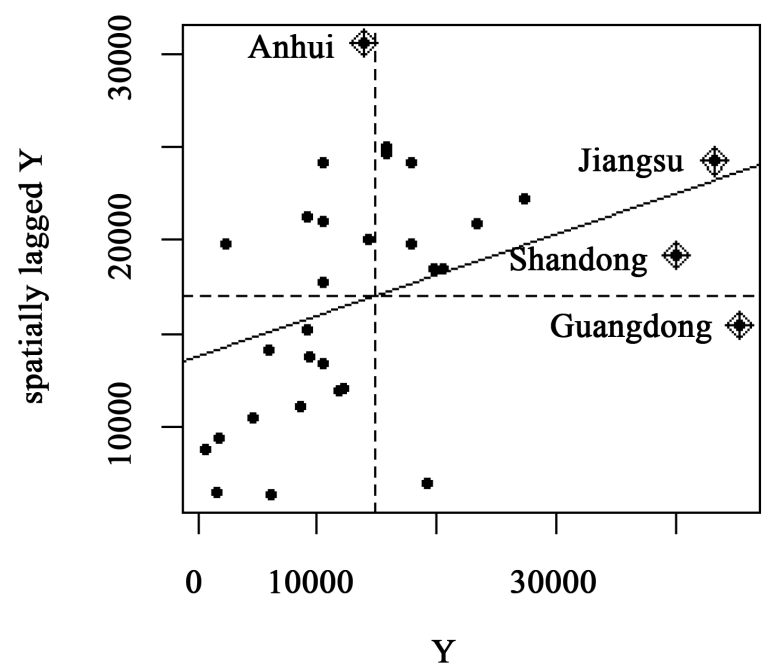

Figure 1. Mroan's I scatter diagram of GDP. 


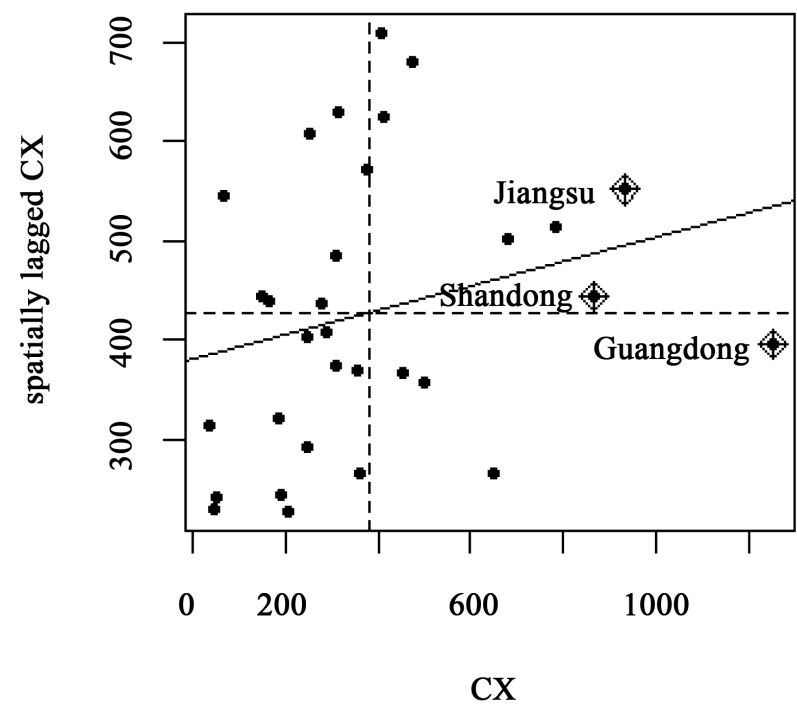

Figure 2. Mroan's I scatter diagram of junior school and education below.

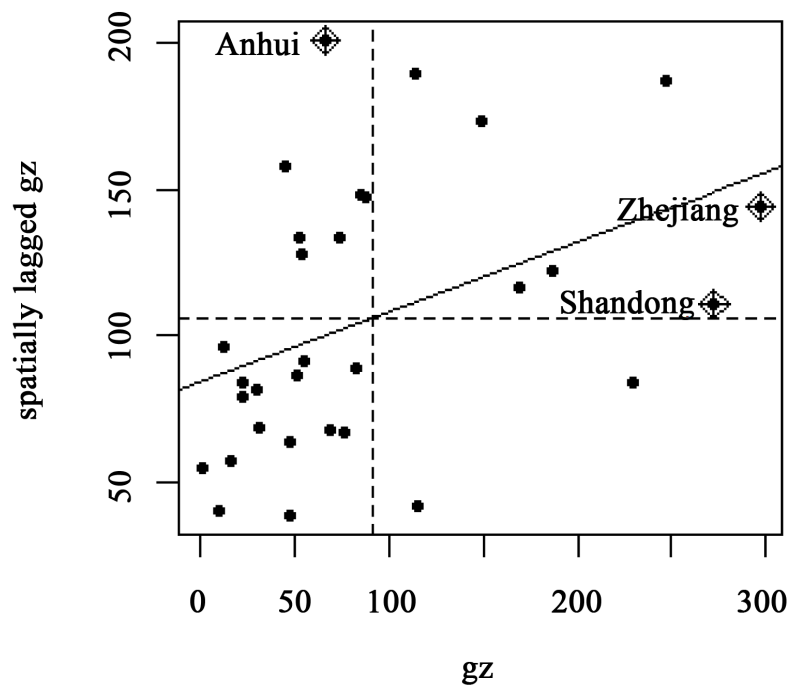

Figure 3. Scatter diagram of vocational and technical education output.

as follows, and $\mathrm{P}$ values of parameters are included in parentheses.

It can be seen from estimation results of time period during 2006-2010 (Table 2), $\lambda$ is greater than zero, indicating that there's the spatial spillover effect of labors with various education levels, which has the obvious clustering effect. This may be related to the strong mobility of labors, the changes of urban labor input variables can affect GDP level of cities nearby. In this time period, labors with junior school education or below have the largest contribution to economic growth, its role in promoting the economy even more than physical capital investment. While labors with vocational and technical education and labors with regular higher education in this period have played similar roles in promoting the economy, but their role is far less than the labors with junior school education or below.

It can be known from the estimation results of the latest time period during 2011-2014 (Table 3) that the role of labors with junior school education or below in promoting economic growth is changed from positive to negative. This is also related to universal increased education level of China's labors in recent years, and the sharp decline of number of labors with junior school education or below. The role of labors with vocational and 


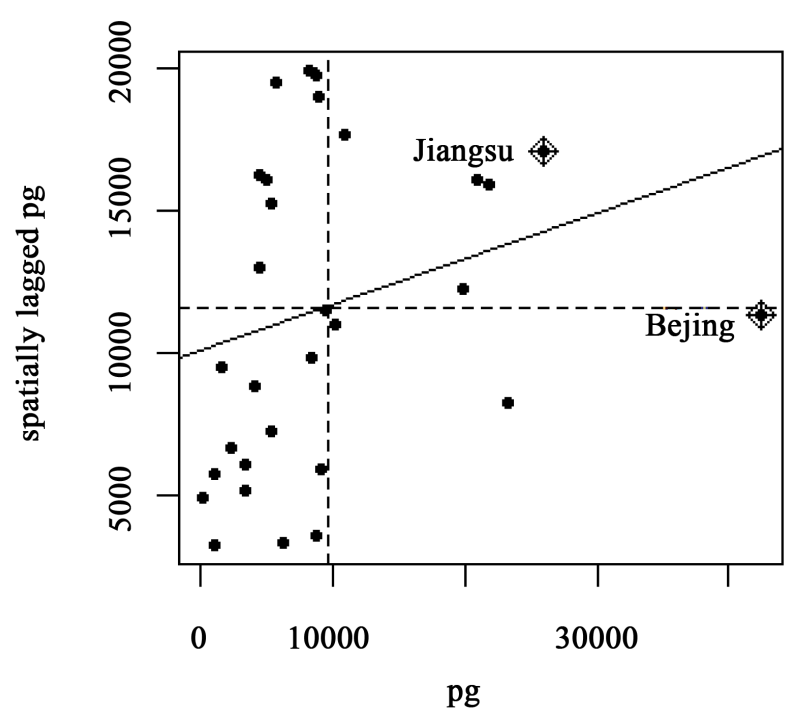

Figure 4. Education output Moran's I diagram of regular higher education.

Table 2. SEM model estimation result table during 2006-2010.

\begin{tabular}{|c|c|c|c|c|}
\hline Parameter & Random effect & Fixed space & Fixed time & Fixed space and time \\
\hline \multirow[t]{2}{*}{ C } & $1.6635^{* * *}$ & $3.8166^{* * *}$ & -0.0707 & $5.0677^{* * *}$ \\
\hline & $(2.68 \mathrm{E}-15)$ & $(2.20 \mathrm{E}-16)$ & $(0.6658)$ & $(1.39 \mathrm{E}-12)$ \\
\hline \multirow[t]{2}{*}{$\lambda$} & $1.9286^{* *}$ & $0.4690^{* * *}$ & $0.2526^{*}$ & -0.1914 \\
\hline & $(0.0055)$ & $(7.65 E-08)$ & $(0.0157)$ & $(0.1201)$ \\
\hline \multirow[t]{2}{*}{$\ln K$} & $0.3989^{* * *}$ & $0.4061^{* * *}$ & $0.7940^{* * *}$ & $0.2756^{* * *}$ \\
\hline & $(2.20 \mathrm{E}-16)$ & $(2.20 \mathrm{E}-16)$ & $(2.20 \mathrm{E}-16)$ & $(3.61 \mathrm{E}-08)$ \\
\hline \multirow[t]{2}{*}{$\ln L_{1}$} & $0.5484^{* * *}$ & $0.1791^{*}$ & $0.2182^{* * *}$ & $0.1641^{*}$ \\
\hline & $(2.20 \mathrm{E}-16)$ & $(0.01982)$ & $(1.31 \mathrm{E}-09)$ & $(0.0281)$ \\
\hline \multirow[t]{2}{*}{$\ln L_{2}$} & $0.1060^{* *}$ & $0.0126^{* *}$ & $0.0823^{* * *}$ & $0.0207^{* *}$ \\
\hline & $(0.0157)$ & $(0.0451)$ & $(0.0001)$ & $(0.0330)$ \\
\hline \multirow[t]{2}{*}{$\ln L_{3}$} & $0.1132^{* * *}$ & 0.0241 & $0.1755^{* * *}$ & 0.0183 \\
\hline & $(0.0002)$ & $(0.4224)$ & $(7.71 \mathrm{E}-10)$ & $(0.50766)$ \\
\hline
\end{tabular}

Note: “*”, “**”, ““***”, represent to pass the significance test at respective level of $10 \%, 5 \%$ and $1 \%$.

technical education in promoting the economic growth is also changed from positive to negative, which is also consistent with the actual situation of China's "shortage of skilled workers" in recent years. Since most of educated children of this generation are from the only one child families, those families attach great importance to higher education of their children, and they are not too willing to send their children to vocational and technical schools, coupled with enlarged enrollment policy in regular higher colleges and universities, and therefore, regular higher education has played the strongest role in promoting economic growth. However, there's no substantial contribution according to the coefficient, substantially GDP is increased by more than $20 \%$ per increase of $1 \%$ labors with regular higher education. 
Table 3. SEM model estimation result table during 2011-2014.

\begin{tabular}{|c|c|c|c|c|}
\hline Parameter & Random effect & Fixed space & Fixed time & Fixed space and time \\
\hline \multirow[t]{2}{*}{ C } & $3.4584^{* * *}$ & $3.9933^{* * *}$ & 0.0141 & $4.6854^{* * * *}$ \\
\hline & $(2.20 \mathrm{E}-16)$ & $(2.20 \mathrm{E}-16)$ & $(0.9175)$ & $(2.20 \mathrm{E}-16)$ \\
\hline \multirow[t]{2}{*}{$\lambda$} & $1.9286^{* *}$ & 0.0106 & -0.0170 & 0.0053 \\
\hline & $(0.0055)$ & $(0.4030)$ & $(0.2658)$ & $(0.7568)$ \\
\hline \multirow[t]{2}{*}{$\ln K$} & $0.4538^{* * * *}$ & $0.4583^{* * *}$ & $0.7539^{* * * *}$ & $0.3875^{* * *}$ \\
\hline & $(0.0000)$ & $(0.0000)$ & $(0.0000)$ & $(0.0000)$ \\
\hline \multirow[t]{2}{*}{$\ln L_{1}$} & $-0.1661^{* * *}$ & $-0.0677^{*}$ & $-0.2164^{* * *}$ & $-0.0729^{*}$ \\
\hline & $(0.0000)$ & $(0.0253)$ & $(0.0000)$ & $(0.0194)$ \\
\hline \multirow[t]{2}{*}{$\ln L_{2}$} & -0.0262 & -0.0207 & $-0.0967^{* * *}$ & -0.0208 \\
\hline & $(0.8298)$ & $(0.6295)$ & $(0.0092)$ & $(0.3573)$ \\
\hline \multirow[t]{2}{*}{$\ln L_{3}$} & $0.2618^{* * * *}$ & $0.2377^{* *}$ & $0.2244^{* * *}$ & 0.2256 \\
\hline & $(0.0039)$ & $(0.0623)$ & $(0.0000)$ & $(0.1734)$ \\
\hline
\end{tabular}

Note: ““”, ““*”, “***” represent to pass the significance test at respective level of $10 \%, 5 \%$ and $1 \%$.

Seen from 2006-2014 (Table 4), the labors with junior school education or below have overall the largest elastic coefficient in promoting economic growth, but elastic coefficient in promoting economic growth becomes much smaller compared to the time period during 2006-2010. With the social progress and improvement of education level, it's indeed unfeasible to drive the economic growth by long-term relying on the labors with junior school education or below; there's a more rapid increase of the number of labors with regular higher education in recent years, but on the whole it does not have played large role in promoting the economic growth; in general, the elasticity of the vocational and technical education is negative, which in fact is not optimistic for China. It's essential to encourage the vocational and technical education, and expand the number of enrollment of vocational and technical education, and also focus on culturing the vocational and technical personnel.

It can be seen from Hausman test results of estimation tables of the three time periods above that $\mathrm{P}$ value of the test is far less than 0.01 , indicating that null hypothesis of random selection effect can be rejected, and three models are with better fixed effects. According to the foregoing presentation on principle of the spatial effects, the tables of direct and indirect effects of models with better fixed effects obtained through calculation are shown as follows.

It can be seen from spatial effect of various variables during 2006-2010 (Table 5) that direct effect is always greater than the indirect effect, indicating that the human capital of local region plays a greater role in promoting the economic growth of the region. However, indirect effect of human capital when there's fixed spatial is greater than the indirect effect when time is fixed, indicating that a certain time is required for the spillover effects of human capital, the human capital of some area will affect the economic growth of the contiguity regions with the passage of time.

It can be known from spatial effect of variables during 2011-2014 (Table 6) that direct effect is always greater than the indirect effect, but the spatial effects of labors with junior school education or below, and also labors with vocational and technical education are negative, indicating that the education level of human capital in recent years is in favor of regular higher education. With the upgrading of the education level, it's reasonable for the reduction of labors with the junior school education or below. However, the human capital with vocational and technical education has played a role that is irreplaceable for human capital of regular higher education in promoting the social development, the youth are blindly biased to the regular higher education, which is actually uneconomical and unreasonable no matter for individuals or the country.

It can be seen from spatial effect of various variables during 2006-2010 (Table 7) as a whole that direct effect is always greater than the indirect effect, where the spatial effect of the labors with junior school education or 
Table 4. SEM model estimation result table during 2006-2014.

\begin{tabular}{|c|c|c|c|c|}
\hline Parameter & Random effect & Fixed space & Fixed time & Fixed space and time \\
\hline \multirow[t]{2}{*}{ C } & $3.4019^{* * *}$ & $4.3274^{* * * *}$ & 0.2267 & $5.0219^{* * *}$ \\
\hline & $(2.20 \mathrm{E}-16)$ & $(2.20 \mathrm{E}-16)$ & $(0.2844)$ & $(2.20 \mathrm{E}-16)$ \\
\hline \multirow[t]{2}{*}{$\lambda$} & $1.9286^{* * *}$ & $0.7920^{* * *}$ & 0.1241 & $0.2596^{*}$ \\
\hline & $(0.0055)$ & $(2.00 \mathrm{E}-16)$ & $(0.32242)$ & $(0.0258)$ \\
\hline \multirow[t]{2}{*}{$\ln K$} & $0.5116^{* * *}$ & $0.4579^{* * *}$ & 0.6865 & $0.3833^{* * *}$ \\
\hline & $(2.20 \mathrm{E}-16)$ & $(2.00 \mathrm{E}-16)$ & $(2.20 \mathrm{E}-16)$ & $(2.00 \mathrm{E}-16)$ \\
\hline \multirow[t]{2}{*}{$\ln L_{1}$} & $0.0897^{* * *}$ & $0.0423^{*}$ & $0.1953^{* * * *}$ & $0.0510^{*}$ \\
\hline & $(0.0002)$ & $(0.0247)$ & $(3.61 \mathrm{E}-07)$ & $(0.01171)$ \\
\hline \multirow[t]{2}{*}{$\ln L_{2}$} & -0.0021 & -0.0131 & $-0.0824^{*}$ & -0.0152 \\
\hline & $(0.9011)$ & $(0.1808)$ & $(0.0160)$ & $(0.1695)$ \\
\hline \multirow[t]{2}{*}{$\ln L_{3}$} & $0.0520^{* *}$ & -0.0009 & $0.3038^{* * *}$ & 0.0024 \\
\hline & $(0.0648)$ & $(0.9685)$ & $(2.20 \mathrm{E}-16)$ & $(0.9162)$ \\
\hline
\end{tabular}

Note: “*”, ““*”, “***” represent to pass the significance test at respective level of $10 \%, 5 \%$ and $1 \%$.

Table 5. Spatial effect of fixed effect model during 2006-2010.

\begin{tabular}{|c|c|c|c|c|c|c|c|c|c|}
\hline & \multicolumn{3}{|c|}{ Fixed space } & \multicolumn{3}{|c|}{ Fixed time } & \multicolumn{3}{|c|}{ Fixed time and space } \\
\hline & Direct effect & Indirect effect & Total effect & Direct effect & $\begin{array}{l}\text { Indirect } \\
\text { effect }\end{array}$ & Total effect & Direct effect & Indirect effect & Total effect \\
\hline K & 0.2873 & 0.1237 & 0.4111 & 0.7390 & $2.13 \mathrm{E}-04$ & 0.7392 & 1.0264 & 0.1240 & 1.1503 \\
\hline$L_{1}$ & 0.1231 & 0.0530 & 0.1761 & 0.2350 & $6.76 \mathrm{E}-05$ & 0.2351 & 0.3581 & 0.0531 & 0.4112 \\
\hline$L_{2}$ & 0.0168 & 0.0072 & 0.0240 & 0.1076 & $3.10 \mathrm{E}-05$ & 0.1077 & 0.1244 & 0.0073 & 0.1317 \\
\hline$L_{3}$ & 0.0160 & 0.0069 & 0.0228 & 0.2322 & $6.68 \mathrm{E}-05$ & 0.2322 & 0.2481 & 0.0069 & 0.2551 \\
\hline
\end{tabular}

Table 6. Spatial effect of fixed effect model during 2011-2014.

\begin{tabular}{cccccccccc}
\hline & \multicolumn{3}{c}{ Fixed space } & & \multicolumn{3}{c}{ Fixed time } & \multicolumn{3}{c}{ Fixed space and time } \\
\cline { 2 - 10 } & Direct effect Indirect effect & Total effect & Direct effect & $\begin{array}{c}\text { Indirect } \\
\text { effect }\end{array}$ & Total effect & Direct effect & Indirect effect & Total effect \\
\hline$K$ & 0.3141 & 0.1829 & 0.4970 & 0.6756 & 0.0030 & 0.6786 & 0.3929 & 0.0804 & 0.4733 \\
$L_{1}$ & -0.0143 & -0.0083 & -0.0226 & -0.2067 & -0.0009 & -0.2076 & -0.2210 & -0.0093 & -0.2302 \\
$L_{2}$ & -0.0751 & -0.0438 & -0.1189 & -0.0864 & -0.0004 & -0.0868 & -0.0193 & -0.0039 & -0.0232 \\
$L_{3}$ & 0.0935 & 0.0545 & 0.1479 & 0.3066 & 0.0014 & 0.3080 & 0.0045 & 0.0009 & 0.0054 \\
\hline
\end{tabular}

Table 7. Spatial effect of fixed effect model during 2006-2014.

\begin{tabular}{cccccccccc}
\hline & \multicolumn{3}{c}{ Fixed space } & & \multicolumn{3}{c}{ Fixed time } & \multicolumn{2}{c}{ Fixed space and time } \\
\cline { 2 - 8 } & Direct effect Indirect effect & Total effect & Direct effect & Indirect effect & Total effect & Direct effect & Indirect effect & Total effect \\
\hline$K$ & 0.3551 & 0.1069 & 0.4620 & 0.7390 & $2.13 \mathrm{E}-04$ & 0.7392 & 1.0942 & 0.1071 & 1.2013 \\
$L_{1}$ & 0.0570 & 0.0171 & 0.0741 & 0.2322 & $6.68 \mathrm{E}-05$ & 0.2322 & 0.2892 & 0.0172 & 0.3064 \\
$L_{2}$ & -0.0284 & -0.0085 & -0.0369 & -0.1076 & $-3.10 \mathrm{E}-05$ & -0.1077 & -0.1360 & -0.0086 & -0.1446 \\
$L_{3}$ & 0.0404 & 0.0121 & 0.0525 & 0.2350 & $6.76 \mathrm{E}-05$ & 0.2351 & 0.2754 & 0.0122 & 0.2876 \\
\hline
\end{tabular}


below, and the labors with regular higher education are positive, while the employees with vocational and technical education is negative, various human capitals in promoting the economic growth in contiguity region is with time delay, which can't be ignored.

\section{Main Conclusions and Recommendations}

It could be known through the econometric model analysis of the three time periods of 2006-2010, 2011-2014 and 2006-2014 that because of the high mobility of human resources, the labors of various education outputs of each time period were with the spatial spillover characteristics. Although the spatial direct effect of each time period is greater than the indirect effect, the indirect effect can't be ignored, and the human capital between contiguity regions will affect economic growth of the region. The proportion of China's labors with junior school education or below during 2006-2010 was relatively large, which was more obvious in driving the economic growth. The scale of labors with regular higher education at the time period is not too large, the driving effect on economic growth is not obvious enough; the effect of labors with vocational and technical education on economic growth of the time period is positive. However, with the continuous improvement of China's education level in recent years, and the expansion of higher education scale, there's a relatively large scale of reduction of labors with junior school education or below, and some part of labors with vocational and technical education is also transformed to the higher education. Therefore, the effect of labors with vocational and technical education on economic growth is transformed from positive to negative, which is actually unreasonable but also not conducive to China's sustainable development for the long-term. Because first of all the labors with vocational and technical education have strong professional skills, and they play the role that is irreplaceable for labors with regular higher education, especially for manufacturing, construction and other industries focusing more on the operating ability, and practice ability of labors. Secondly, the labors require more time for achieving the higher education, and they also consume more social resources, and therefore the efficiency of educational output is not high. In addition, many labors with vocational and technical education do not require the senior school education, they not only learn the during the required courses of senior high school during the school education period, and also learn a highly professional vocational skill, so as to effectively participate into the corresponding social work after graduation. Finally, the current society has a very large demand for skilled personnel with the vocational and technical education, and with China's great success in the $43^{\text {th }}$ WorldSkills, China begins to attach great importance to vocational and technical education.

Therefore, the followed education for China's students with junior school education or above should:

First, China should pay more attention to vocational and technical education, and focus on the labors with vocational and technical education, improving their social status, broadening their development prospects. In the process of developing the higher education, China should apply some certain resources to the development of the vocational and technical education, so as to cultivate more professional and technical personnel, skilled personnel, and good players of the WorldSkills, thereby improving China's international status in terms of skills.

Second, China should not neglect the spatial indirect effect while paying attention to the spatial direct effect, and China should strengthen human capital flow, narrowing the gap between human capital quality and quantity between regions. Cities below first tier should pay more attention to the indirect effect of such space, introducing the appropriate talent introduction policies to attract and retain more personnel, so as to narrow the gap between cities in China to ease population pressure in some first-tier cities and population aging issues of some cities, thereby achieving the common development and sustainable development throughout the country.

\section{References}

[1] Mao, S.Y. and Liu, Y.Y. (2010) Labor Force of Higher Education and Economic Growth of China-Analysis on the Panel Data of 1999-2007.

[2] Fang, G. and Wang, X.L. (2011) Study on the Contribution of Chinese Marketization to Economic Growth. Economic Research, No. 9, 4-16.

[3] Wang, X.L., Fang, G. and Liu, P. (2009) Study on the Transformation of Economic Growth Mode and Sustainable Growth of China. Economy, No. 1, 44-47.

[4] Wang, X.Z. (2014) Research Methods of Application of Regional Economics: Application Based on Arcgis, Geoda and R.

[5] Elhorst, J.P. (2009) Spatial Panel Data Models. In: Fischer, M.M. and Getis, A., Eds., Handbook of Applied Spatial Analysis, Springer, Berlin, 377-408. 